\title{
NSC Number
}

National Cancer Institute

\section{Source}

National Cancer Institute. NSC Number. NCI Thesaurus. Code C41243.

A numeric identifier for substances submitted to the National Cancer Institute $(\mathrm{NCl})$ for testing and evaluation. It is named after the Cancer Chemotherapy National Service Center (CCNSC), created in 1955, which originally ran the testing program and assigned these numbers. The testing program and repository is now run by the $\mathrm{NCl}$ Developmental Therapeutics Program (DTP). Assignment of NSC numbers was never done in a way that would guarantee one and only one NSC number would be assigned to a particular substance. 